\title{
Editorial Note: Storage, Computation and Security of Multimedia Social Networks on Cloud Environment
}

Published online: 14 December 2018

Multimedia Tools and Applications gratefully acknowledges the editorial work of the scholars listed below on the special issue entitled, "Storage, Computation and Security of Multimedia Social Networks on Cloud Environment."

Of 30 papers submitted to this issue, 9 were eventually accepted after a stringent peer-review process.

\section{Dr. B. B. Gupta (Corresponding Guest Editor)}

National Institute of Technology Kurukshetra, India

bbgupta.nitkkr@gmail.com

\section{Dr. Michael Sheng}

Macquarie University, Sydney, Australia

michael.sheng@mq.edu.au

\section{Dr. Dharma P. Agrawal}

OBR Distinguished Professor, University of Cincinnati, Cincinnati, USA

dpa@cs.uc.edu

Publisher's Note Springer Nature remains neutral with regard to jurisdictional claims in published maps and institutional affiliations. 